Article

\title{
Switchable Interfaces: Redox Monolayers on Si(100) by Electrochemical Trapping of Alcohol Nucleophiles
}

\author{
Long Zhang ${ }^{1,2}$, Ruth Belinda Domínguez Espíndola ${ }^{1}$, Benjamin B. Noble ${ }^{3}$, \\ Vinicius R. Gonçales ${ }^{4}\left(\mathbb{D}\right.$, Gordon G. Wallace ${ }^{2}$, Nadim Darwish ${ }^{1, *}$, Michelle L. Coote ${ }^{3, *}$ (D) \\ and Simone Ciampi ${ }^{1, *}$ \\ 1 School of Molecular and Life Sciences, Curtin Institute of Functional Molecules and Interfaces, Curtin \\ University, Bentley, Western Australia 6102, Australia; long.zhang@unsw.edu.au (L.Z.); \\ rdominguez@uaem.mx (R.B.D.E.) \\ 2 ARC Centre of Excellence for Electromaterials Science, Intelligent Polymer Research Institute, University of \\ Wollongong, Wollongong, New South Wales 2500, Australia; gwallace@uow.edu.au \\ 3 ARC Centre of Excellence for Electromaterials Science, Research School of Chemistry, Australian National \\ University, Canberra, Australian Capital Territory 2601, Australia; benjamin.noble@anu.edu.au \\ 4 School of Chemistry, The University of New South Wales, Sydney, New South Wales 2052, Australia; \\ v.goncales@unsw.edu.au \\ * Correspondence: nadim.darwish@curtin.edu.au (N.D.); michelle.coote@anu.edu.au (M.L.C.); \\ simone.ciampi@curtin.edu.au (S.C.); Tel.: +61-8-9266-9009 (S.C.)
}

Received: 29 June 2018; Accepted: 17 July 2018; Published: 20 July 2018

\begin{abstract}
Organic electrosynthesis is going through its renaissance but its scope in surface science as a tool to introduce specific molecular signatures at an electrode/electrolyte interface is under explored. Here, we have investigated an electrochemical approach to generate in situ surface-tethered and highly-reactive carbocations. We have covalently attached an alkoxyamine derivative on an $\mathrm{Si}(100)$ electrode and used an anodic bias stimulus to trigger its fragmentation into a diffusive nitroxide (TEMPO) and a surface-confined carbocation. As a proof-of-principle we have used this reactive intermediate to trap a nucleophile dissolved in the electrolyte. The nucleophile was ferrocenemethanol and its presence and surface concentration after its reaction with the carbocation were assessed by cyclic voltammetry. The work expands the repertoire of available electrosynthetic methods and could in principle lay the foundation for a new form of electrochemical lithography.
\end{abstract}

Keywords: electrosynthesis; switchable surfaces; alkoxyamine surfaces; redox monolayers

\section{Introduction}

Synthetic organic electrochemistry traces its origin back to the work of Faraday and Kolbe and its green credentials are currently prompting a renaissance [1-3]. Chemical reactions that are coupled to the flow of electricity allow, for instance, chemists to generate unstable intermediates in situ, to control very precisely and accurately the supply of reactants and to monitor reaction processes in real-time [4]. While the large majority of the work on synthetic electrochemistry has focused on bulk synthesis $[5,6]$, there is also a strong motivation to expand electrochemical synthetic methods toward the chemical modification of interfaces [7-10]. Addressing the molecular details of a surface [11], especially those of semiconductors, has been central to the development of fields such as molecular electronics [12], sensing [13], energy conversion [14] and cell biology [15]. Semiconductor electrodes and in particular silicon electrodes, have the advantage of being readily available in a crystalline form, they have unique photo-electrochemical properties and can form covalently-bound monolayers [16]. Silicon like all non-oxide semiconductors is thermodynamically unstable and especially under anodic polarization in aqueous environments tends to grow an electrically-insulating silica layer $[17,18]$. A common 
laboratory approach to attach covalently organic molecules on silicon substrates is a three-step wet chemical process. Removal of the native silica layer with fluoride-containing solutions is followed by chemical passivation [19] of the hydrogen-terminated silicon surface by means of hydrosilylation of terminal alkenes or alkynes [20-22] and finally chemical derivatization of the aliphatic monolayer [16]. In this work we seek to expand the chemical repertoires of this last step and explore the synthetic scope of reactive carbocations in the context of surface chemistry.

There are several methods to generate carbocations in solution [23] but only few examples are available for electrochemical generation of carbocations at electrodes. We have recently reported on the putative generation of carbocations at metallic electrodes after the fragmentation of anodic intermediates of alkoxyamines. Alkoxyamines are heat-labile molecules, widely used as an in situ source of nitroxides in polymer and materials sciences. We have shown that the one-electron oxidation of an alkoxyamine leads to an anodic intermediate that rapidly fragments releasing a nitroxide species at room temperature [24].

In the current work we have developed a surface model system to explore the feasibility of using surface-tethered carbocations to trap solution nucleophiles. The carbocation is electro-generated in situ from an alkoxyamine molecule that is exposed at the distal end of an organic monolayer grown on a $\mathrm{Si}(100)$ electrode. By way of applying a positive bias to the $\mathrm{Si}(100)$ electrode, the alkoxyamine is anodically cleaved to release a 2,2,6,6-tetramethylpiperidine-1-oxyl (TEMPO) molecule and generate a surface-confined carbocation species. The latter is attacked by electron donors via nucleophilic substitutions. As proof-of-principle we have prepared redox-active monolayers by generating the surface carbocations in the presence of ferrocenemethanol (2) molecules.

\section{Materials and Methods}

\subsection{Chemicals}

All chemicals, unless specified otherwise, were of analytical grade and used as received. Milli- $\mathrm{Q}^{\mathrm{TM}}$ water ( $>18 \mathrm{M} \Omega \mathrm{cm}$, Millipore Corporation, Burlington, MA, USA) was used to prepare solutions and to clean all glassware. Anhydrous solvents used in chemical reactions were purified under nitrogen by a solvent drying system from LC Technology Solutions Inc. Dichloromethane (DCM), methanol $(\mathrm{MeOH})$ and 2-propanol were redistilled prior to use. Hydrogen peroxide (30 wt \% in water), ammonium fluoride (Puranal ${ }^{\mathrm{TM}}, 40 \mathrm{wt} \%$ in water) and sulfuric acid (Puranal ${ }^{\mathrm{TM}}, 95-97 \%$ ) were used to clean the wafers and were of semiconductor grade. 1,8-nonadiyne (Sigma-Aldrich, 98\%) was redistilled from sodium borohydride (Sigma-Aldrich, 99+\%) under reduced pressure $\left(80{ }^{\circ} \mathrm{C}, 10-12\right.$ Torr) and stored under a high purity argon atmosphere prior to use. Tetrabutylammonium hexafluorophosphate salt $\left(\mathrm{Bu}_{4} \mathrm{NPF}_{6}\right.$, Sigma-Aldrich, $\left.\geq 98 \%\right)$ was used as a supporting electrolyte. 4-Vinylbenzyl chloride (90\%), ammonium sulphite, ferrocene (98\%), ferrocenemethanol (2, 97\%) and 2,2,6,6-tetramethylpiperidine-1-oxyl (TEMPO hereafter, $98 \%)$ were purchased from Sigma-Aldrich. The surface reactive (azide-tagged) alkoxyamine 1-(1-(4-azidomethyl)phenyl)ethoxy-2,2,6,6-tetramethylpiperidine (1) was synthesized according to minor modification of previously reported procedure (see Scheme 1) [25]. Prime grade, single-side polished silicon wafers of 100-orientation $\left(<100> \pm 0.5^{\circ}\right)$, p-type (boron-doped) of $100 \mathrm{~mm}$ diameter, $500-550 \mu \mathrm{m}$ thickness and of a nominal resistivity of $0.001-0.003 \Omega \mathrm{cm}$ were obtained from Siltronix, S.A.S. (Archamps, France). 


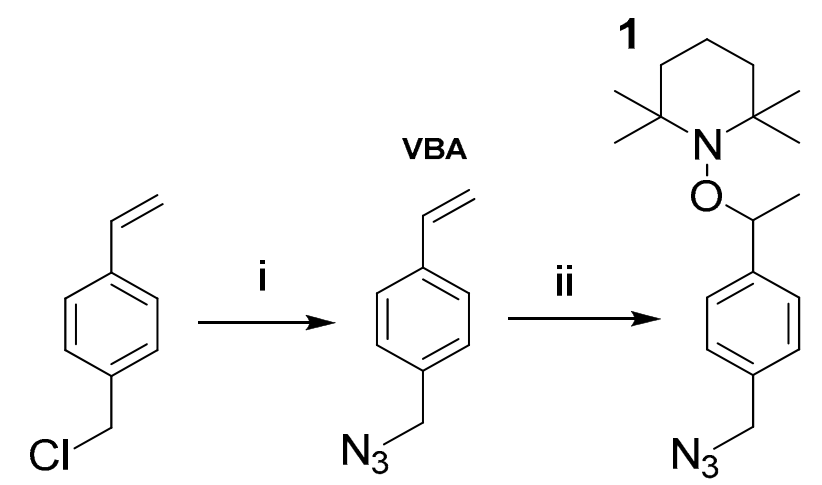

Scheme 1. Synthesis of the azide-tagged alkoxyamine 1. i. $\mathrm{NaN}_{3}, \mathrm{DMF}, 82 \%$. ii. TEMPO, $\mathrm{Mn}(\mathrm{OAc})_{3} \cdot 2 \mathrm{H}_{2} \mathrm{O}, \mathrm{NaBH}_{4}$, Toluene/EtOH, $50 \%$.

\subsection{Synthetic Methods}

Thin-layer chromatography (TLC) was performed on silica gel Merck aluminium sheets $\left(60 \mathrm{~F}_{254}\right)$. Merck 60 A silica gel (220-400 mesh particle size) was used for column chromatography. Nuclear magnetic resonance (NMR) spectra were recorded on a Bruker Avance 400 spectrometer in deuterated dimethyl sulfoxide (d-DMSO) using the residual solvent signal as internal reference. High-resolution mass spectral data (HRMS, mass accuracy $2-4 \mathrm{ppm}$ ) of alkoxyamine 1 were obtained using a Waters Xevo QTof MS via ESI experiments and infusing the sample at $8 \mu \mathrm{L} / \mathrm{min}$.

Synthesis of 4-Vinylbenzyl azide (VBA). Sodium azide $(1.30 \mathrm{~g}, 20 \mathrm{mmol})$ was added in one portion to a stirred solution of 4-vinylbenzyl chloride (1.53 g, $10 \mathrm{mmol})$ in $\mathrm{N}, \mathrm{N}$-dimethylformamide (DMF, $20 \mathrm{~mL}$ ). The reaction mixture was stirred at room temperature for $12 \mathrm{~h}$ under argon then poured into a large excess water $(100 \mathrm{~mL})$. The mixture was extracted with $\mathrm{DCM}(3 \times 50 \mathrm{~mL})$. The combined organic layers were then washed with brine $(2 \times 100 \mathrm{~mL})$, dried over $\mathrm{MgSO}_{4}$, filtered and dried under vacuum to afford the crude title compound as a brown oily residue. The crude material was purified by silica gel column chromatography (hexane) to give VBA as a light yellow oil $(1.31 \mathrm{~g}, 82 \%) .{ }^{1} \mathrm{H} \mathrm{NMR}(400 \mathrm{MHz}$, d-DMSO): $\delta 7.50$ p.p.m. (d, Ar-H, $J=8.12 \mathrm{~Hz}, 2 \mathrm{H}), 7.35$ (d, $\mathrm{Ar}-\mathrm{H}, J=8.04 \mathrm{~Hz}, 2 \mathrm{H}), 6.74$ (dd, $\mathrm{Ar}-\mathrm{CH}=\mathrm{CH}_{2}$, $J=17.66 \mathrm{~Hz}, 1 \mathrm{H}), 5.85\left(\mathrm{dd}, \mathrm{Ar}-\mathrm{CH}=\mathrm{CH}_{2}, J=17.68 \mathrm{~Hz}, 0.96 \mathrm{~Hz}, 1 \mathrm{H}\right), 5.28\left(\mathrm{dd}, \mathrm{Ar}-\mathrm{CH}=\mathrm{CH}_{2}, J=11.84 \mathrm{~Hz}\right.$, $0.92 \mathrm{~Hz}, 1 \mathrm{H}), 4.43\left(\mathrm{~s}, \mathrm{Ar}-\mathrm{CH}_{2}-\mathrm{N}_{3}, 2 \mathrm{H}\right) ;{ }^{13} \mathrm{C}$ NMR $(100 \mathrm{MHz}, \mathrm{d}-\mathrm{DMSO}): \delta 136.96,136.11,135.13,128.69$, $126.39,114.64,53.32$.

Synthesis of 1-(1-(4-Azidomethyl) phenyl)ethoxy-2,2,6,6-tetramethylpiperidine (1). Alkoxyamine $\mathbf{1}$ was synthesized from VBA via the following procedure. To an ice-cold solution of TEMPO $(0.31 \mathrm{~g}, 2 \mathrm{mmol})$ in toluene/ethanol $(60 \mathrm{~mL}, 1: 1, \mathrm{v} / \mathrm{v}) \mathrm{VBA}(3.20 \mathrm{~g}, 20 \mathrm{mmol})$ and $\mathrm{Mn}(\mathrm{OAc})_{3} \cdot 2 \mathrm{H}_{2} \mathrm{O}(5.36 \mathrm{~g}, 20 \mathrm{mmol})$ were added in one portion while stirring in air. Stirring was continued for one min and then a 15-fold molar excess (with respect to TEMPO) of $\mathrm{NaBH}_{4}$ was added in portions over $15 \mathrm{~min}$. After stirring overnight under nitrogen atmosphere, the residue was isolated by filtration, the filtrate was suspended in water and the aqueous solution was then extracted three times with DCM. The combined organic layers were evaporated under vacuum and the crude material was purified by silica gel column chromatography (ethyl acetate/hexane, 1:40, v/v) to yield alkoxyamine $\mathbf{1}$ as a colourless oil liquid $(0.32 \mathrm{~g}, 50 \%)$.

${ }^{1} \mathrm{H}$ NMR (400 MHz, d-DMSO): $\delta$ 7.36-7.29 p.p.m. (m, Ar-H, 4H), 4.75 (q, NO-CH-Ar, $J=13.50 \mathrm{~Hz}$, $1 \mathrm{H}), 4.42\left(\mathrm{~s}, \mathrm{~N}_{3}-\mathrm{CH}_{2}-\mathrm{Ar}, 2 \mathrm{H}\right), 1.54-1.38(\mathrm{~m}, 6 \mathrm{H}), 1.37-1.19(\mathrm{~m}, 6 \mathrm{H}), 1.12(\mathrm{~s}, 3 \mathrm{H}), 0.97(\mathrm{~s}, 3 \mathrm{H}), 0.57(\mathrm{~s}, 3 \mathrm{H})$; ${ }^{13} \mathrm{C}$ NMR (100 MHz, d-DMSO): $\delta$ 145.08, 134.08, 128.21, 126.76, 82.09, 59.22, 58.98, 53.40, 33.99, 33.76, 23.00, 20.04, 16.66; HRMS (1, $m / z)$ : $[\mathrm{M}+\mathrm{H}]^{+}$calcd for $\mathrm{C}_{18} \mathrm{H}_{29} \mathrm{~N}_{4} \mathrm{O}$ 317.2336, found 317.2335. 


\subsection{Surface Modification}

\subsubsection{Light-Assisted Hydrosilylation of 1,8-Nonadiyne on $\mathrm{Si}(100)$ (S-1)}

The assembly of the acetylenylated $\mathrm{Si}(100)$ surface by covalent attachment of 1,8-nonadiyne on hydrogen-terminated silicon is based on a photochemical hydrosilylation method [26]. In brief, silicon wafers were mechanically cut into pieces (approximately $10 \times 10 \mathrm{~mm}$ in size), rinsed several times with small portions of $\mathrm{DCM}, \mathrm{MeOH}$ and Milli- $\mathrm{Q}^{\mathrm{TM}}$ water. The samples were then immersed in hot Piranha solution $\left(100{ }^{\circ} \mathrm{C}\right.$, a $3: 1(\mathrm{v} / \mathrm{v})$ mixture of concentrated sulfuric acid to $30 \%$ hydrogen peroxide, Caution: piranha solution reacts violently with organic substances) for $20 \mathrm{~min}$. The samples were then rinsed with water and immediately etched with a deoxygenated $40 \%$ aqueous ammonium fluoride solution for $5 \mathrm{~min}$ under a stream of argon. A small amount (ca. $5 \mathrm{mg}$ ) of ammonium sulphite was added to the etching bath for building an anaerobic environment and hence avoiding the in situ oxidation of the hydrogen-terminated silicon. The freshly etched samples were washed sequentially with Milli- $\mathrm{Q}^{\mathrm{TM}}$ water and DCM and blown dry with argon before dropping a small deoxygenated sample of 1,8-nonadiyne (approximate $50 \mu \mathrm{L}$ ) on the hydrogen-terminated wafer and covering it with a quartz slide to minimize evaporation. The wafer was then rapidly transferred to an air-tight UV reaction chamber and kept under positive argon pressure. A collimated LED source $(\lambda=365 \mathrm{~nm}$, nominal power output $>190 \mathrm{~mW}$, Thorlabs part M365L2 coupled to a SM1P25-A collimator adapter) was fixed over the sample at a distance of about $10 \mathrm{~cm}$. After illumination for a $2 \mathrm{~h}$ period, the resulting acetylene-functionalized sample (S-1, Scheme 2) was removed from the reaction chamber, rinsed several times with DCM and rested for $12 \mathrm{~h}$ in a sealed vial at $+4{ }^{\circ} \mathrm{C}$ under DCM before being further reacted with alkoxyamine 1.

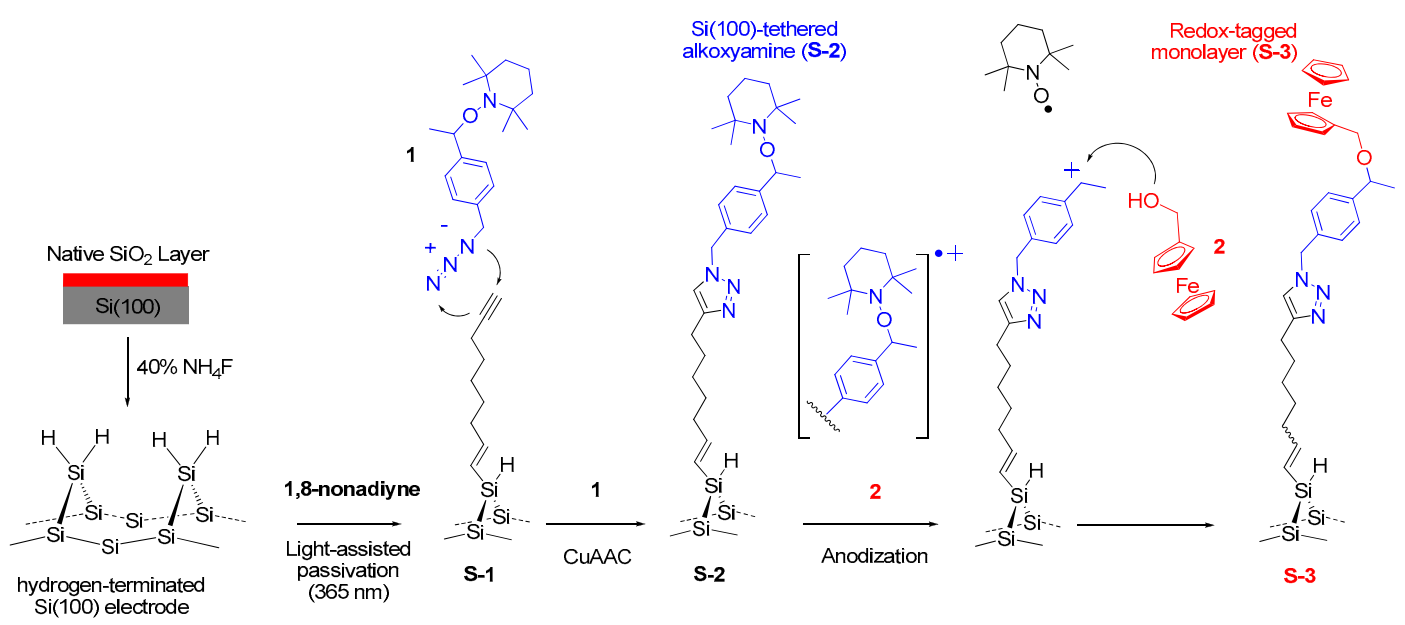

Scheme 2. Light-assisted (365 nm) hydrosilylation of 1,8-nonadiyne to passivate an hydrogenterminated $\mathrm{Si}(100)$ surface (S-1) and covalent attachment of alkoxyamine $\mathbf{1}$ via CuAAC "click" reactions to yield an alkoxyamine monolayer (S-2). Anodization of S-2 in the presence of the alcohol nucleophile 2 leads to release of TEMPO in the electrolyte with formation of a redox-active monolayer (S-3) by reaction of $\mathbf{2}$ with the putative surface-tethered carbocation intermediate.

\subsubsection{Click Immobilization of Alkoxyamine $\mathbf{1}$ (S-2)}

Surface S-1 was reacted with molecule $\mathbf{1}$ to yield the alkoxyamine monolayers (S-2) via a copper(I)-catalysed "click" alkyne-azide cycloaddition (CuAAC) reaction. In brief, to a reaction vial containing the alkyne-functionalized silicon surface (S-1) was added (i) the azide (alkoxyamine 1, $0.5 \times 10^{-3} \mathrm{M}$, 2-propanol/water, 1:1, v/v), (ii) copper(II) sulphate pentahydrate $\left(1.0 \times 10^{-4} \mathrm{M}\right)$ and (iii) sodium ascorbate $(5 \mathrm{mg} / \mathrm{mL})$. The reaction was carried out without excluding air from the reaction environment, at room temperature and under ambient light. The samples were removed from 
the reaction vessel after a reaction time of $2 \mathrm{~h}$ and were rinsed thoroughly with copious amounts of 2-propanol, water, 2-propanol and DCM and blown dry with argon before being analysed or further reacted (Scheme 2).

\subsection{Surface Characterization}

\subsubsection{X-ray Photoelectron Spectroscopy}

X-ray photoelectron spectroscopy (XPS) characterization was performed on an ESCALab $250 \mathrm{Xi}$ (Thermo Scientific, Waltham, MA, USA) spectrometer with a monochromated Al K $\alpha$ source to characterize the formation of an alkoxyamine $\mathbf{1}$ monolayer on silicon. The pressure in the analysis chamber during measurement was $<10^{-8}$ mbar. The pass energy and step size for narrow scans were $20 \mathrm{eV}$ and $0.1 \mathrm{eV}$ respectively, with a take-off angle normal to the sample surface. Spectral analysis was performed using Avantage 4.73 software and curve fitting was carried out with a mixture of Gaussian-Lorentzian functions after background subtraction. Peaks were calibrated to C-C at $284.8 \mathrm{eV}$.

\subsubsection{Electrochemical Measurements}

Electrochemical experiments were performed in a single-compartment, three-electrode PTFE cell with the modified silicon surface as the working electrode, a platinum mesh (ca. $200 \mathrm{~mm}^{2}$ ) as the counter electrode and silver/silver chloride "leakless" electrode in $3 \mathrm{M}$ sodium chloride as the reference electrode. A rectilinear cross-section gasket defined the geometric area of the working electrode to $28 \mathrm{~mm}^{2}$. Electrical contact between the silicon substrate and a copper plate was ensured by rapidly rubbing a gallium indium eutectic onto the back of the silicon electrode. Cyclic voltammetry (CV) measurements were performed using a $\mathrm{CHI}$ 910B electrochemical analyser. All potentials are reported versus the reference electrode. Tetrabutylammonium hexafluorophosphate $\left(\mathrm{Bu}_{4} \mathrm{NPF}_{6}\right.$, Sigma-Aldrich, $\geq 98 \%$ ) was recrystallized twice from 2-propanol and used at the concentration of $1.0 \times 10^{-1} \mathrm{M}$ as the supporting electrolyte in DCM solutions. The reaction between the anodically-cleaved S-2 samples and ferrocenemethanol (2), as well as control experiments were $\mathbf{2}$ is replaced by ferrocene, were performed under argon and at room temperature. S-3 samples (Scheme 2) were thoroughly washed with DCM prior to analysis. Cyclic voltammetry of $\mathbf{S}-\mathbf{3}$ samples was performed under ambient conditions in aqueous $1.0 \mathrm{M} \mathrm{HClO}_{4}$ electrolytes.

\section{Results and Discussion}

As a proof-of-principle, we have devised "trapping" experiments on an electrode surface modified by alkoxyamine $\mathbf{1}$ (S-2, Scheme 2). The anodization of the S-2 monolayers is expected to generate benzylic cations tethered on the electrode surface while the nitroxide fragment is released into the electrolyte. The covalent attachment of alkoxyamine $\mathbf{1}$ to the silicon surface was first verified by the XPS (Figure 1). Peaks at 99.3 and $100.0 \mathrm{eV}$ for $\mathbf{S}-2$ samples were respectively ascribed to the $S i 2 \mathrm{p}_{3 / 2}$ and Si $2 \mathrm{p}_{1 / 2}$ emissions (Figure 1b). The presence of a band at $101.1-104.3 \mathrm{eV}$ is due to $\mathrm{SiO}_{x}$ formed during the hydrosilylation and/or CuAAC processes. Two signals in the carbon envelope that are centred at 284.6 and $286.3 \mathrm{eV}$ indicates the formation of C-C and C-O/-N, respectively [27], as expected for the putative structure of S-2 samples (Figure 1c). As shown in Figure 1d, refinement of the N 1s emission gives two fitted peaks with binding energies of 400.5 and $401.7 \mathrm{eV}$ in an approximate 3:1 ratio. The position of the low binding energy line in the S-2 samples is in agreement with the $400.6 \mathrm{eV}$ previously assigned to nitroxide nitrogen atoms in thin films [22]. Electrons from the triazole heterocycle also contributed to the 400.5 and 401.7 emissions with an expected 2:1 ratio. 

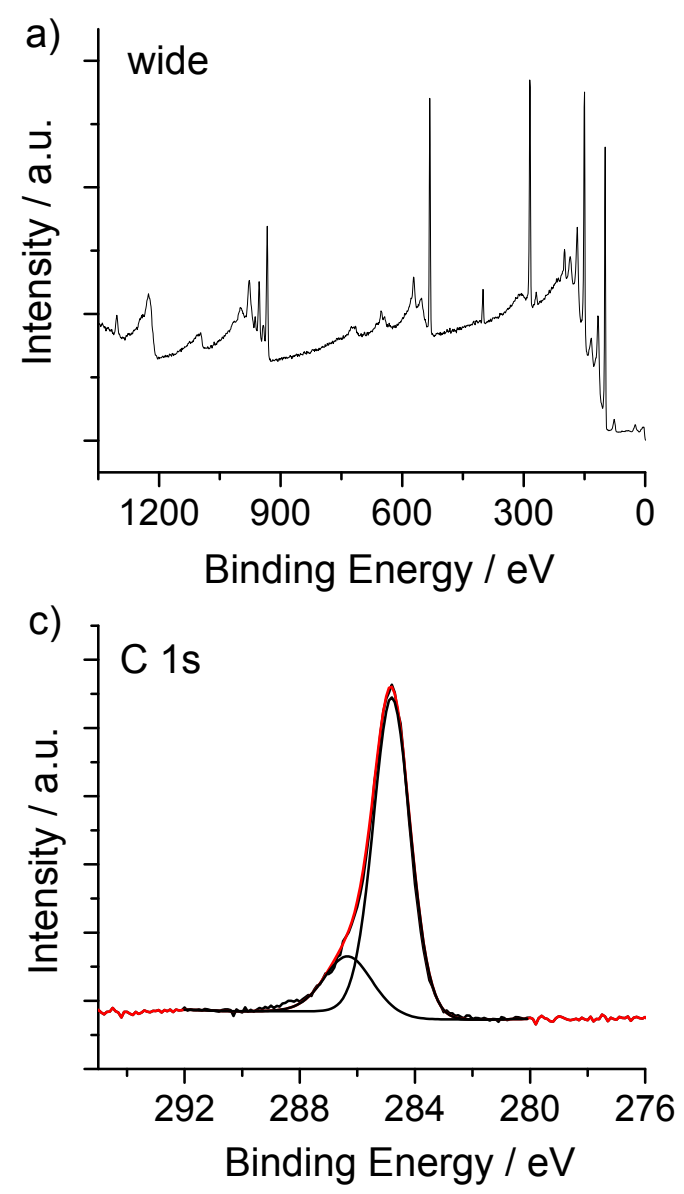
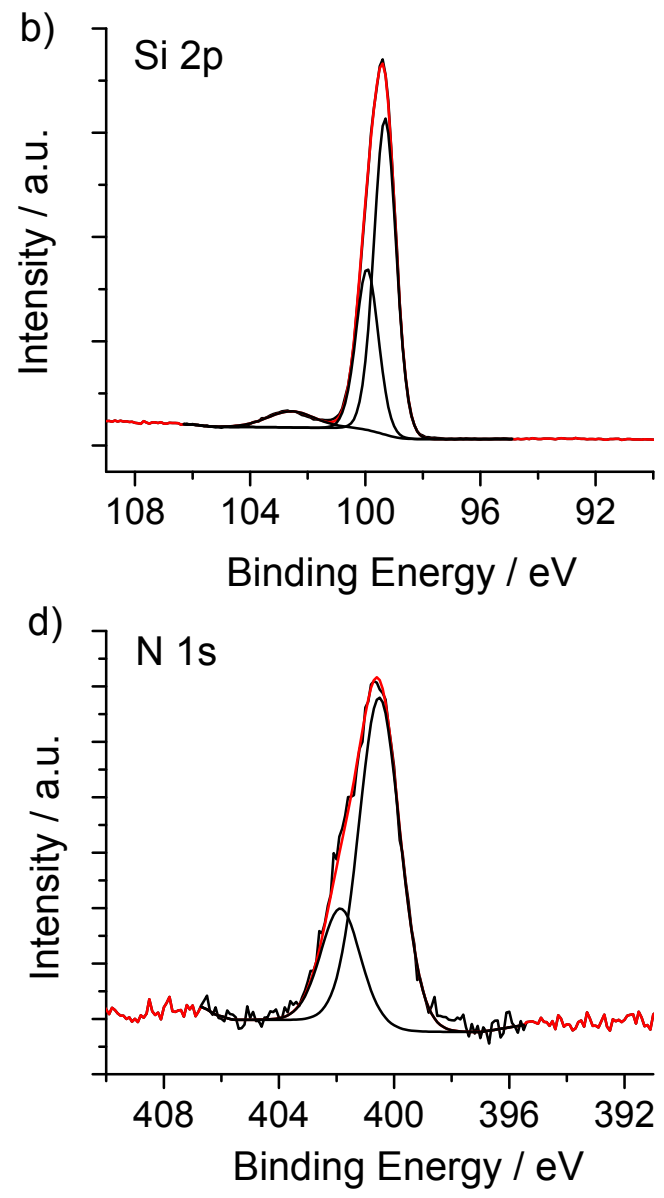

Figure 1. XPS survey spectra (a) and high-resolution Si 2p (b), C 1s (c) and N 1s (d) scans of $\mathbf{S}-2$ samples assembled on high-doped p-type $\mathrm{Si}(100)$ surface by $\mathrm{CuAAC}$ reactions between alkoxyamine $\mathbf{1}$ and alkyne-terminated monolayers (S-1).

As shown Figure 2, the anodization of the alkoxyamine monolayer (S-2) via a potentiostatic experiment (electrode held at $1.0 \mathrm{~V}$ versus reference for $30 \mathrm{~s}$ ) in $1.0 \times 10^{-1} \mathrm{M} \mathrm{DCM} / \mathrm{Bu}_{4} \mathrm{NPF}_{6}$ in the presence of an excess of $\mathbf{2}$ is effective in trapping the alcohol at the distal end of the monolayer. The newly-formed redox-active surface (S-3) is washed with copious DCM and then analysed by cyclic voltammetry in an electrolyte that does not contain a redox-active species. Figure 2a shows the well-defined pair of redox waves (solid red lines) which are ascribed to the surface-confined redox tag (S-3). The surface coverage of ferrocenyl units, derived from integration of the anodic wave, ranges over almost on order of magnitude from $5.5 \times 10^{-12} \mathrm{~mol} \mathrm{~cm}^{-2}$, as the low end, up to the value of $3.1 \times 10^{-11} \mathrm{~mol} \mathrm{~cm}^{-2}$ for our highest current yield. Our best result is still only about $10 \%$ of close-packed packed layer of redox ferrocenes; defining the exact nature of any competitive side-reactions is beyond the scope of this work. Two control experiments were carried out as follows. We used ferrocene, which lacks the hydroxyl function, to rule out non-specific adsorption of the redox probe as well as trying to remove the anodic step. That is, the working electrode modified bearing the alkoxyamine 1 is rested at open circuit potential (OCP) conditions in the presence of the nucleophile (2). In both controls (Figure 2b) we found no evidence of redox peaks when either the nucleophile is removed from the system (+, Figure $2 \mathrm{~b}$ ) or when the $\mathbf{S}-\mathbf{2}$ surface is not anodized to trigger the switch masked alkoxyamine/reactive carbocation $(\bigcirc$, Figure $2 b)$. 
a)

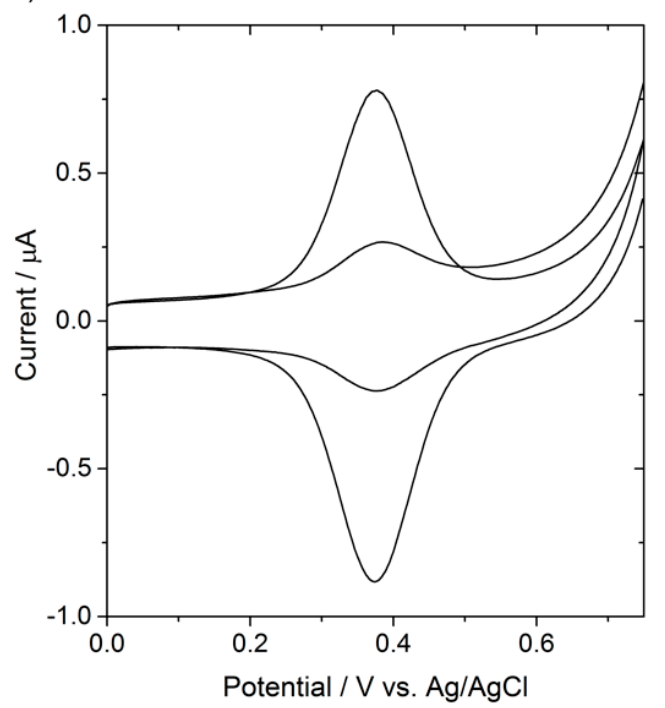

b)

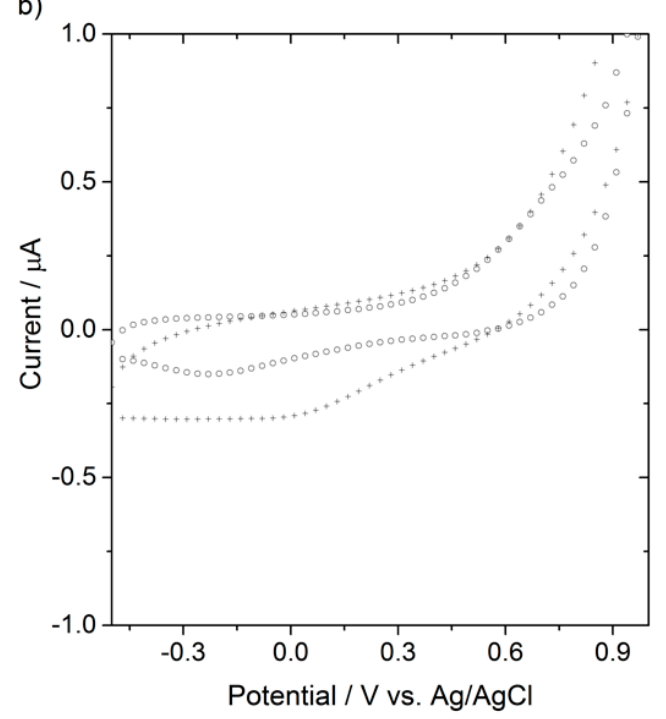

Figure 2. Cyclic voltammograms (CVs) of redox nucleophiles reacted with the anodized alkoxyamines monolayer (conversion of S-2 into S-3). CVs were acquired at a voltage sweep rate of $100 \mathrm{mV} \mathrm{s}^{-1}$. (a) CVs analysis of the $\mathrm{Si}(100)$ electrode in $1.0 \mathrm{M} \mathrm{HClO}_{4}$ after the anodization of $\mathbf{S - 2}$ monolayers in the presence of ferrocene methanol (2) with the surface coverage of ferrocene units ranging from $5.5 \times$ $10^{-12} \mathrm{~mol} \mathrm{~cm}^{-2}$, as the low end, up to the value of $3.1 \times 10^{-11} \mathrm{~mol} \mathrm{~cm}^{-2}$. (b) Control experiments for prolonged standing of S-2 electrodes at open circuit potential in the presence of $\mathbf{2}$ in the electrolyte $(\bigcirc)$ or CVs for the experiments as in (a) but with ferrocene replacing $2(+)$.

\section{Conclusions}

We have demonstrated a method to achieve a switchable interface-from unreactive to electrophilic - and used it to attach alcohol species as monolayers on Si(100) electrodes. Unlike conventional esterification approaches on surfaces (e.g., DCC/DMAP), here we show an electrochemical alternative that involves a surface carbocation. This reactive intermediate is generated in situ under an external potential stimulus that switches a stable alkoxyamine into a reactive surface trap for nucleophiles. This proof-of-principle expands to the realm of surfaces some of the recent advances made in synthetic organic electrochemistry. This knowledge may aid the development of cationic polymerization on surfaces and this surface chemistry platform can in principle be coupled to photo-electrochemical reactions on semiconductors and photoconductors [26] in order to control electron transfer, hence chemical reactivity, in two dimensions [28,29].

Author Contributions: Conceptualization, S.C.; Data curation, L.Z. and S.C.; Formal analysis, L.Z., B.B.N., M.L.C. and S.C.; Funding acquisition, G.G.W., N.D., M.L.C. and S.C.; Investigation, L.Z., R.B.D.E., V.R.G. and S.C.; Methodology, S.C.; Project administration, S.C.; Resources, G.G.W., M.L.C. and S.C.; Supervision, G.G.W. and S.C.; Validation, R.B.D.E.; Visualization, L.Z.; Writing—original draft, L.Z.; Writing—review \& editing, V.R.G., N.D., M.L.C. and S.C.

Funding: This work was supported by grants from the Australian Research Council (DE160100732 (S.C.), DE160101101 (N.D.), CE 140100012 (L.Z., B.B.N., M.L.C. and G.G.W.)).

Acknowledgments: We acknowledge support from Curtin University's Microscopy \& Microanalysis Facility, whose instrumentation has been partially funded by the University, State and Commonwealth. L.Z. would like to thank AINSE Ltd. for providing financial assistance. M.L.C. gratefully acknowledges an ARC Georgina Sweet ARC Laureate Fellowship.

Conflicts of Interest: The authors declare no conflict of interest. 


\section{References}

1. Horn, E.J.; Rosen, B.R.; Baran, P.S. Synthetic organic electrochemistry: An enabling and innately sustainable method. ACS Cent. Sci. 2016, 2, 302-308. [CrossRef] [PubMed]

2. Yan, M.; Kawamata, Y.; Baran, P.S. Synthetic organic electrochemical methods since 2000: On the verge of a renaissance. Chem. Rev. 2017, 117, 13230-13319. [CrossRef] [PubMed]

3. Yan, M.; Kawamata, Y.; Baran, P.S. Synthetic organic electrochemistry: Calling all engineers. Angew. Chem. Int. Ed. 2018, 57, 4149-4155. [CrossRef] [PubMed]

4. Frontana-Uribe, B.A.; Little, R.D.; Ibanez, J.G.; Palma, A.; Vasquez-Medrano, R. Organic electrosynthesis: A promising green methodology in organic chemistry. Green Chem. 2010, 12, 2099-2119. [CrossRef]

5. Gütz, C.; Selt, M.; Bänziger, M.; Bucher, C.; Römelt, C.; Hecken, N.; Gallou, F.; Galvão, T.R.; Waldvogel, S.R. A novel cathode material for cathodic dehalogenation of 1, 1-dibromo cyclopropane derivatives. Chem. Eur. J. 2015, 21, 13878-13882. [CrossRef] [PubMed]

6. Gütz, C.; Bänziger, M.; Bucher, C.; Galvão, T.S.R.; Waldvogel, S.R. Development and scale-up of the electrochemical dehalogenation for the synthesis of a key intermediate for NS5A inhibitors. Org. Process Res. Dev. 2015, 19, 1428-1433. [CrossRef]

7. Andrieux, C.P.; Gonzalez, F.; Savéant, J.-M. Derivatization of carbon surfaces by anodic oxidation of arylacetates. Electrochemical manipulation of the grafted films. J. Am. Chem. Soc. 1997, 119, 4292-4300. [CrossRef]

8. Robins, E.; Stewart, M.; Buriak, J. Anodic and cathodic electrografting of alkynes on porous silicon. Chem. Commun. 1999, 2479-2480. [CrossRef]

9. Hurley, P.T.; Ribbe, A.E.; Buriak, J.M. Nanopatterning of alkynes on hydrogen-terminated silicon surfaces by scanning probe-induced cathodic electrografting. J. Am. Chem. Soc. 2003, 125, 11334-11339. [CrossRef] [PubMed]

10. Belanger, D.; Pinson, J. Electrografting: A powerful method for surface modification. Chem. Soc. Rev. 2011, 40, 3995-4048. [CrossRef] [PubMed]

11. Gooding, J.J.; Ciampi, S. The molecular level modification of surfaces: From self-assembled monolayers to complex molecular assemblies. Chem. Soc. Rev. 2011, 40, 2704-2718. [CrossRef] [PubMed]

12. Aragonès, A.C.; Darwish, N.; Ciampi, S.; Sanz, F.; Gooding, J.J.; Díez-Pérez, I. Single-molecule electrical contacts on silicon electrodes under ambient conditions. Nat. Commun. 2017, 8, 15056-15063. [CrossRef] [PubMed]

13. Scheres, L.; ter Maat, J.; Giesbers, M.; Zuilhof, H. Microcontact printing onto oxide-free silicon via highly reactive acid fluoride-functionalized monolayers. Small 2010, 6, 642-650. [CrossRef] [PubMed]

14. Bard, A.J.; Bocarsly, A.B.; Fan, F.R.F.; Walton, E.G.; Wrighton, M.S. The concept of Fermi level pinning at semiconductor/liquid junctions. Consequences for energy conversion efficiency and selection of useful solution redox couples in solar devices. J. Am. Chem. Soc. 1980, 102, 3671-3677. [CrossRef]

15. Ciampi, S.; James, M.; Le Saux, G.; Gaus, K.; Justin Gooding, J. Electrochemical “switching” of Si(100) modular assemblies. J. Am. Chem. Soc. 2012, 134, 844-847. [CrossRef] [PubMed]

16. Ciampi, S.; Harper, J.B.; Gooding, J.J. Wet chemical routes to the assembly of organic monolayers on silicon surfaces via the formation of $\mathrm{Si}-\mathrm{C}$ bonds: Surface preparation, passivation and functionalization. Chem. Soc. Rev. 2010, 39, 2158-2183. [CrossRef] [PubMed]

17. Ciampi, S.; Eggers, P.K.; Le Saux, G.; James, M.; Harper, J.B.; Gooding, J.J. Silicon (100) Electrodes resistant to oxidation in aqueous solutions: An unexpected benefit of surface acetylene moieties. Langmuir 2009, 25, 2530-2539. [CrossRef] [PubMed]

18. Noufi, R.; Frank, A.J.; Nozik, A.J. Stabilization of n-type silicon photoelectrodes to surface oxidation in aqueous electrolyte solution and mediation of oxidation reaction by surface-attached organic conducting polymer. J. Am. Chem. Soc. 1981, 103, 1849-1850. [CrossRef]

19. Nemanick, E.J.; Hurley, P.T.; Webb, L.J.; Knapp, D.W.; Michalak, D.J.; Brunschwig, B.S.; Lewis, N.S. Chemical and electrical passivation of single-crystal silicon(100) surfaces through a two-step chlorination/alkylation process. J. Phys. Chem. B 2006, 110, 14770-14778. [CrossRef] [PubMed]

20. Linford, M.R.; Chidsey, C.E.D. Alkyl monolayers covalently bonded to silicon surfaces. J. Am. Chem. Soc. 1993, 115, 12631-12632. [CrossRef] 
21. Sun, Q.-Y.; de Smet, L.C.P.M.; van Lagen, B.; Wright, A.; Zuilhof, H.; Sudhöelter, E.J.R. Covalently attached monolayers on hydrogen-terminated Si(100): Extremely mild attachment by visible light. Angew. Chem. Int. Ed. 2004, 43, 1352-1355. [CrossRef] [PubMed]

22. Zhang, L.; Vogel, Y.B.; Noble, B.B.; Gonçales, V.R.; Darwish, N.; Brun, A.L.; Gooding, J.J.; Wallace, G.G.; Coote, M.L.; Ciampi, S. TEMPO monolayers on Si(100) electrodes: Electrostatic effects by the electrolyte and semiconductor space-charge on the electroactivity of a persistent radical. J. Am. Chem. Soc. 2016, 138, 9611-9619. [CrossRef] [PubMed]

23. Yoshida, J.-I.; Kataoka, K.; Horcajada, R.; Nagaki, A. Modern strategies in electroorganic synthesis. Chem. Rev. 2008, 108, 2265-2299. [CrossRef] [PubMed]

24. Zhang, L.; Laborda, E.; Darwish, N.; Noble, B.B.; Tyrell, J.H.; Pluczyk, S.; Le Brun, A.P.; Wallace, G.G.; Gonzalez, J.; Coote, M.L. Electrochemical and electrostatic cleavage of alkoxyamines. J. Am. Chem. Soc. 2018, 140, 766-774. [CrossRef] [PubMed]

25. Danko, M.; Szabo, E.; Hrdlovic, P. Synthesis and spectral characteristics of fluorescent dyes based on coumarin fluorophore and hindered amine stabilizer in solution and polymer matrices. Dyes Pigments 2011, 90, 129-138. [CrossRef]

26. Vogel, Y.B.; Zhang, L.; Darwish, N.; Gonçales, V.R.; Le Brun, A.; Gooding, J.J.; Molina, A.; Wallace, G.G.; Coote, M.L.; Gonzalez, J. Reproducible flaws unveil electrostatic aspects of semiconductor electrochemistry. Nat. Commun. 2017, 8, 2066. [CrossRef] [PubMed]

27. Ciampi, S.; Böcking, T.; Kilian, K.A.; James, M.; Harper, J.B.; Gooding, J.J. Functionalization of acetylene-terminated monolayers on $\mathrm{Si}(100)$ surfaces: A click chemistry approach. Langmuir 2007, 23, 9320-9329. [CrossRef] [PubMed]

28. Choudhury, M.H.; Ciampi, S.; Yang, Y.; Tavallaie, R.; Zhu, Y.; Zarei, L.; Gonçales, V.R.; Gooding, J.J. Connecting electrodes with light: One wire, many electrodes. Chem. Sci. 2015, 6, 6769-6776. [CrossRef] [PubMed]

29. Vogel, Y.B.; Gonçales, V.R.; Gooding, J.J.; Ciampi, S. Electrochemical microscopy based on spatial light modulators: A projection system to spatially address electrochemical reactions at semiconductors. J. Electrochem. Soc. 2018, 165, H3085-H3092. [CrossRef] 